\title{
Performance of Statens Serum Institut Enteric Medium for Detection of Enteric Pathogens in Stool in Routine Laboratory Diagnostics
}

\author{
Peter Shigoli $^{1{ }^{* *}}$, Gunturu Revathi ${ }^{2}$, Elusah Juliet ${ }^{3}$, Kimang'a Nyerere ${ }^{1}$ \\ ${ }^{1}$ Department of Medical Microbiology, Jomo Kenyatta University of Agriculture and Technology, Kenya \\ ${ }^{2}$ Department of Pathology, Aga Khan University Hospital Nairobi, Kenya \\ ${ }^{3}$ Department of Biological Science, University of Eldoret, Kenya
}

Copyright (C) 2015 by authors, all rights reserved. Authors agree that this article remains permanently open access under the terms of the Creative Commons Attribution License 4.0 International License

\begin{abstract}
Background: We evaluated the performance of Statens Serum Institut enteric medium (SSI) for detection of enteric pathogens in stool in two routine diagnostic laboratories in Nairobi to determine if the detection in stool would be most sensitive and specific in our culture protocol. Methods: Salmonella-Shigella agar (SS), Statens Serum Institut enteric medium (SSI), Deoxycholate Citrate Agar (DCA) and MacConkey media were prepared according to the manufacture's institutions. Diarrheal stool specimens received at the laboratory for routine diagnosis were streaked directly and after enrichment in Selenite $\mathrm{F}$ onto the test media and incubated for 24 hours at $37^{\circ}$ Centigrade. After incubation, the growth characteristics and chemical reactions was compared with the manual given. Results: SSI medium was a more productive medium in the detection of enteric pathogens in comparison to the other three media $(\mathrm{F}=2.729$, d. $f=3$ at $p \leq 0.005$ ). It also shows that enrichment of the specimens in Selenite F enhances recovery. Conclusion: SSI enteric medium yields differentiating biochemical reactions that allow direct identification of a range of enteric pathogens thus saving on time and costs. Our revised/modified protocol, where we plated stool samples after enrichment in selenite F broth onto SS and SSI, achieved a high sensitivity of detection and optimal isolation.
\end{abstract}

Keywords Enterobacteriaceae, Diarrhoea, Media

\section{Introduction}

Detection of Enteric Pathogens in Stool using conventional media, such as MacConkey and Salmonella-Shigella agar (SS), is based on lactose fermentation and $\mathrm{H}_{2} \mathrm{~S}$ production [1]. The traditional methodology for routine detection of enteric pathogens nearly always employs a combination of at least three different media in order to increase the sensitivity and the specificity of the detection and identification method. This is due to the fact that if one medium is highly inhibitory to some members of the Enterobacteriaceae, e.g., Escherichia coli, there is a simultaneous loss of sensitivity for fastidious pathogens such as the Shigella spp. [2]. Recently, media with sensitivities and specificities higher than those of conventional media have been developed for the isolation enteric pathogens in stool. One such media is Statens Serum Institut Enteric Medium (SSI) which has been credited with the ability for direct identification of enteric pathogens on the medium, thus providing a more rapid diagnosis [3]. This study evaluated the ability of SSI enteric medium to detect and identify enteric pathogens in comparison to those of other standard enteric media.

\section{Materials and Methods}

This was a cross sectional prospective study approved by the scientific and ethical committees of both Kenyatta National Hospital and the Aga Khan University Hospital, Nairobi. The study utilized specimens received in the laboratories of the two hospitals for routine diagnosis. No samples were obtained solely for the study but rather the study was incorporated in routine diagnosis.

\subsection{Clinical Specimens}

Minimum sample size was determined using Harper's fomular for enteric pathogens. $21 \%$ isolation rate of enteric pathogens from stool was assumed and $5 \%$ level significance [4].

$$
\mathrm{N}=\left\{\mathrm{Z}^{2}+\mathrm{a}(1-\mathrm{P})\right\} / \mathrm{d}^{2}
$$

Where: $Z=1.96$ (standard), $P=21 \%$ isolation rate, $d=0.1(10 \%$ absolute), $\mathrm{a}=0.05$ ( $5 \%$ significance level).

Therefore, $\mathrm{N}=67$ minimum sample size. 
A total of 175 stool samples from two different referral hospitals (46 samples Kenyatta National Hospital (KNH) and 129 samples from the Aga Khan University Hospital $(\mathrm{AKUH}))$ in the city of Nairobi were used for the evaluation of SSI enteric medium. Only major pathogenic species were evaluated for their detection limits in stools and compared for their quantitative growth on the different enteric media.

\subsection{Media Preparation and Culture}

SS, SSI, DCA and MacConkey media (HiMedia Lab, India) were prepared according to the manufacture's instructions. Diarrheal stool specimens received at the laboratory for routine diagnosis were streaked directly and after enrichment in Selenite F (for samples from $\mathrm{KNH}$ ) onto the test media and incubated for 24 hours at $37^{\circ}$ Centigrade. After incubation the growth characteristics and chemical reactions was compared on the SSI media with the SSI identification manual given. For DCA, MacConkey and SS media, further biochemical test were done (Triple Sugar Iron test and serotyping) in order to identify the enteric bacteria. Escherichia coli ATCC 25922, was used on each media as a method of standard control.

\section{Results}

\section{Growth characteristics of enteric bacilli on the SSI enteric medium}

In the inoculated stool samples $(n=129)$ from KNH, 124 gave growth on SSI enteric medium and very few (6 of 129 [3\%]) did not give any growth. Five bacteria (four Escherichia coli and one Aeromonas spp) gave a false-negative reaction for lactose fermentation. One strain of Salmonella typhi did not produce $\mathrm{H}_{2} \mathrm{~S}$ and Morganella spp did not produce phenylalanine deaminase reaction. However, all of these strains expressed the expected reactions in confirmatory tests.

\section{Growth on SSI enteric medium compared to that on DCA medium}

Most of the bacteria (124 of 129 samples [96\%]) grew with little or no inhibition on SSI enteric medium compared to growth on DCA agar (18 of 129 samples [16\%]). Growth on SSI enteric medium was better than that on DCA. This was particularly evident for Klebsiella spp. and Enteropathogenic E. coli (EPEC). The SSI enteric medium also detected Salmonella cholerasius, Citrobacter freundii, and Klyuvera spp (Table 1).

On SSI enteric media, $52 \mathrm{E}$. coli (non pathogenic) were directly identified compared to none on DCA since the bacteria dint give colony characteristics that could make it easily identified on the media. 22 Klebsiella spp were directly identified on SSI media compared to 11 on DCA. 3 enteropathogenic $E$. coli were directly identified on SSI compared to only 1 on DCA. On SSI media, 3 Proteus spp were able to be directly identified compared to only 1 on DCA media. 5 Pseudomonads were directly identified on
SSI compared to only 1 on DCA. One Salmonella enteritidis, Citrobacter freundii, and Klyuvera spp, were able to be directly identified on SSI media but not on DCA media. However, two Salmonella typhi were able to be directly identified on both SSI and DCA media. One Shigella dysentriae, Morganella spp, Salmonella spp, Shigella sonnei, Salmonella typhimurium, Shigella flexneri and one Aeromonas spp were able to be directly identified on both SSI and DCA media.

\section{Growth of non-lactose fermenters on SSI enteric medium compared to that on SS medium}

A total of 15 (11\% of total samples) enteric non-lactose fermenters were able to be directly identified on SSI medium compared to 7 (5\% of total samples) enteric non-lactose fermenters on SS medium (Table 1). However SSI medium was almost able to be matched with SS medium, in identification of Salmonella and Shigella spp (10 species versus 9 species repectively).

\section{Growth on SSI enteric medium compared to that on MacConkey medium}

Most of the enteric bacteria (124 of 129 samples [96\%]) grew with little inhibition on SSI medium compared to that on MacConkey (44 of 129 samples [34\%]). Enteric bacteria species such as Salmonella enteritidis, Citrobacter freundii, Aeromonas hydrophilla, S. flexneri were able to grow and be directly identified on SSI medium but not on MacConkey medium (Table 1). However most lactose fermenters such as E. coli and Klebsiella spp were able to grow and be directly identified on both media.

Table 1. Direct Identification of Enterics on DCA, SSI, SS and MacConkey

\begin{tabular}{|c|c|c|c|c|}
\hline BACTERIA & DCA & SSI & SS & MacConkey \\
\hline E. coli & 0 & 52 & 0 & 20 \\
\hline Klebsiella & 11 & 22 & 0 & 11 \\
\hline EPEC & 1 & 3 & 0 & 1 \\
\hline Proteus & 1 & 3 & 0 & 1 \\
\hline S. typhi & 2 & 2 & 2 & 2 \\
\hline S. dysentriae & 1 & 1 & 1 & 1 \\
\hline $\begin{array}{l}\text { Pseudomonas } \\
\text { spp }\end{array}$ & 1 & 5 & 0 & 3 \\
\hline $\begin{array}{l}\text { Morganella } \\
\text { spp }\end{array}$ & 1 & 1 & 0 & 1 \\
\hline $\begin{array}{l}\text { Salmonella } \\
\text { spp }\end{array}$ & 1 & 1 & 1 & 1 \\
\hline $\begin{array}{l}\text { Salmonella } \\
\text { group D }\end{array}$ & 1 & 1 & 1 & 0 \\
\hline S. enteritidis & 0 & 1 & 1 & 1 \\
\hline S. sonnei & 1 & 1 & 0 & 0 \\
\hline $\begin{array}{c}S . \\
\text { typhimurium }\end{array}$ & 1 & 1 & 1 & 1 \\
\hline S. flexneri & 1 & 1 & 0 & 0 \\
\hline $\begin{array}{l}\text { Citrobacter } \\
\text { freundii }\end{array}$ & 0 & 1 & 0 & 0 \\
\hline $\begin{array}{l}\text { Aeromonas } \\
\text { hydrophilla }\end{array}$ & 1 & 1 & 0 & 0 \\
\hline Kluvyera spp & 0 & 1 & 0 & 1 \\
\hline S. cholerasius & 0 & 1 & 1 & 0 \\
\hline
\end{tabular}


Table 2. Comparative Results of Non Lactose Fermenters (NLFs) Isolation in Salmonella Shigella (SS) and Statens Serum Institut Enteric Medium (SSI) from Direct Culture and Selenite-F Subculture at AKUH.

\begin{tabular}{cccc}
\hline & $\begin{array}{c}\text { Direct } \\
\text { Culture }\end{array}$ & $\begin{array}{c}\text { Selenite-F } \\
\text { Subculture }\end{array}$ & $\begin{array}{c}\text { P-values } \\
\text { ANOVA) }\end{array}$ \\
\cline { 2 - 4 } & $\mathrm{n}=45$ & $\mathrm{n}=45$ & \\
\hline $\mathrm{SS}($ mean $\pm \mathrm{SD})$ & $\begin{array}{c}0.45652 \pm \\
0.50361\end{array}$ & $0.67391 \pm 0.47396$ & 0.05 \\
$\mathrm{SSI}($ mean $\pm \mathrm{SD})$ & $\begin{array}{c}0.84782 \pm \\
0.36315\end{array}$ & $0.95652 \pm 0.20618$ & 0.05 \\
\hline
\end{tabular}

Statens serum institut enteric medium (SSI) showed to be a more productive medium in the detection of enteric pathogens in comparison to Shigella salmonella medium (mean \pm SD: $0.84782 \pm 0.36315 / 0.45652 \pm 0.50361$ ). It also shows that enrichment of the specimens in selenite $\mathrm{F}$ enhances recovery.

One-way ANOVA was used to compare the means of the number of number of bacteria directly identified by the four media. Significant results were observed overall $(F=2.729$, d.f $=3$ at $\mathrm{p} \leq 0.005)$ with SSI medium having the greatest effect.

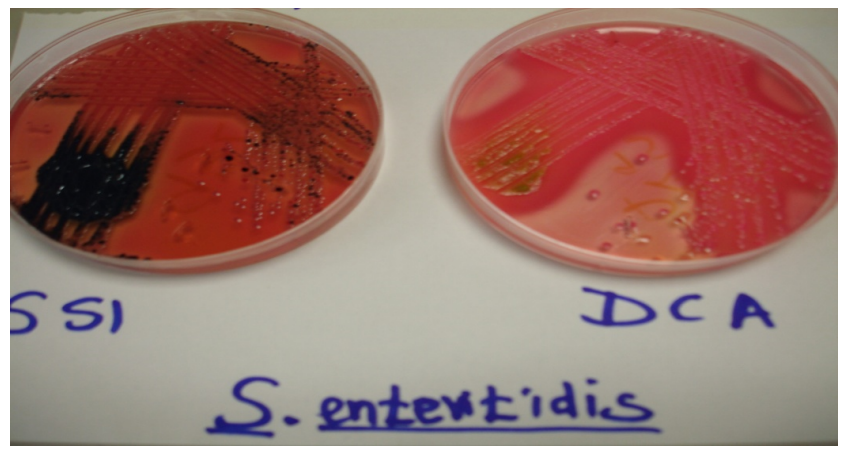

Figure 1. Comparison of colony characteristics on SSI and DCA-hydrogen sulphide production is shown on SSI but is absent on DCA in Salmonella enteritidis. This is due to phenylalanine deaminase reaction in the SSI medium.

\section{Discussion}

The SSI enteric medium evaluated in this study provided the most effective universal medium for the recovery of enteric pathogens. This study also used a modified protocol, in which, we plated stool samples directly and after enrichment in Selenite F broth onto the four media, striving for a high sensitivity of detection and optimal isolation.

There was a significant difference in the isolation characteristics between SSI, DCA, SS and MacConkey. This also is proof that there was a difference in the means in the number of organisms directly identified between the four media hence indicating the SSI media is more superior to other media. The results show that the SSI medium is better or in some cases as good as DCA medium used routinely at the hospital's laboratory, on direct identification of enteric pathogens. This is shown in the percentage of total bacteria isolated on SSI $(76 \%)$ compared to $18 \%$ on DCA. This is a $52 \%$ increase in the direct identification rate of the media.
The SSI medium also supports more distinct growth (124 cases [96\%]) compared to $18(16 \%)$ on DCA medium. This is a $76 \%$ increase in supportive growth of the enteric bacteria. The SSI medium was able to detect most of the chemical reactions produced by the enteric bacteria. This was shown by Hydrogen Sulphide detection in nine out of ten $(90 \%)$ compared to two out of five cases in DCA $(40 \%)$ where Hydrogen Sulphide was produced by the bacteria e.g. Salmonella or Proteus spp. This is a 50\% increase in the detection rate. Phenylalanine deaminase reaction only produced by the SSI medium was detected in eight out of nine cases $(88 \%)$ produced by the bacteria e.g. Morganella or Proteus spp. Rough transformation shown on Shigella spp further proves that the media can directly identify the enteric pathogens. On non-lactose enteric bacteria, the SSI medium was however almost equally matched in identification of Salmonella and Shigella spp as only two Shigella species (S. flexneri and S. sonnei) were not able to be directly identified on SS medium hence needing further serotyping. This close match could be attributed to SS medium being a highly selective media for isolation of Salmonella and Shigella spp from routine clinical specimens [5]. The results also show SSI medium is significantly better than MacConkey medium in direct identification of enteric bacteria. This is shown by the $62 \%$ increase in number of identified enteric bacteria on SSI (96\%) as compared to MacConkey (34\%). This increase is attributed to the dyes and salts present in the composition of MacConkey agar that give similar colony morphology of the bacteria species grown [6]. For example, Klebsiella and Enterobacter spp both would show pink, mucoid colonies on MacConkey, needing further serotyping to distinguish the two but on SSI the manual would be used to distinguish between the two. The direct identification of enteric bacteria on SSI medium thus proves to be a good tool for cost cutting on resources needed to run a routine laboratory, that normally need constant supply of media. It also reduces the time taken for identification of fastidious enteric bacteria hence a better diagnostic tool for quick intervention of enteric diseases.

These results compare well with the findings of Marianne et al., [3] who also found out that the SSI media was able to detect all 248 gram-negative bacterial species that were tested grew on the SSI enteric medium. Only 10 of 248 bacteria $(4 \%)$ showed discrepant results in the biochemical reactions, and none of these were enteric pathogens. Forty-three of 47 enteric pathogens (92\%) produced identical rates of semi quantitative growth on the SSI enteric medium and $5 \%$ blood agar, whereas three Vibrio spp. and one Aeromonas spp. showed reduced growth. They also found out that Gram-positive bacteria did not grow on the SSI enteric medium. The SSI enteric medium also proved its utility during a Vibrio cholerae epidemic in September 1987 in Guinea-Bissau, although the sensitivity of detecting $V$. cholerae was increased with the additional use of thiosulfate-citrate-bile-sucrose (TCBS) agar [7]. The results also compare well with a study done by Wilson [8] who found out that use of SSI gave out a more direct 
identification of enteric bacteria, as compared to traditional three-plate system of use of MacConkey, XLD and DCLS agar for identification of Salmonella and Shigella.

\section{Conclusions}

SSI enteric medium is selective for gram-negative bacteria and allows growth of all aerobic enteric pathogens. The medium is superior to DCA, and its ability to detect Yersinia spp. would limit the number of media needed in a typical laboratory. This media therefore provides a rapid and cost effective means for prompt isolation and diagnosis of pathogenic enterics in a clinical diagnostic laboratory especially in resource strained third world countries. Our revised protocol, where we plated stool samples after enrichment in selenite $\mathrm{F}$ broth onto the media, achieved a high sensitivity of detection and optimal isolation.

\section{Acknowledgements}

Special thanks go out to thank the entire Microbiology Laboratory staff at Aga Khan University Hospital, Nairobi for the assistance given.

\section{REFERENCES}

[1] Saskia VD, Marjan JB, Gijs JH. Evaluation and implementation of a chromogenic agar medium for Salmonella detection in stool in routine laboratory diagnostics. Journal of clinical microbiology. 2009: 47: 456-458.

[2] Taylor WI and Schelhart D. Isolation of Shigellae VIII. Comparison of xylose lysine deoxycholate agar, Hektoen enteric agar, Salmonella-Shigella Agar, and eosin methylene blue agar with stool specimens. Applied microbiology. 2001:21:32-37.

[3] Marianne B, Aase, M, Peter G, Knud G, and Frank E. Evaluation of statens serum institut enteric medium for detection of enteric pathogens. Journal of clinical microbiology. 1999: 37: 2312-2316.

[4] Jekel J, Kartz L and Elmore G. Epidemiology, Biostatistics, and Preventive medicine-Sample size, Randomization, and probability theory. 2001, 2nd edition, 194-208.

[5] Isenberg, H. D. Interpretation of aerobic bacterial growth on primary culture media, Clinical microbiology procedures handbook.1992: 1 1.61-1.67. American Society for Microbiology, Washington, D.C

[6] Anderson and Cindy. Great Adventures in the Microbiology Laboratory .2013. 7th ed. 175-176. Pearson.

[7] Mølbak K, Wested N, Hj'lyng N, Scheutz F, Gottschau A, Aaby P, and Jose' da Silva P. The etiology of early childhood diarrhea: a community study from Guinea-Bissau. Journal of Infectious Disease. 2005:169:581-587.

[8] Wilson G: Evaluation of the combined use of Statens Serum Institut enteric agar and the LOUIS test screening protocol in a Scottish microbiology laboratory. In 15th European Congress of Clinical Microbiology and Infectious Diseases (ECCMID): 02-05 April 2005; Britain. 